\title{
5
}

\section{Surge Analysis for the Proposed OSIS Augmentation Relief Sewer Tunnel}

\author{
M. P. Cherian, Ari Pandian, Karen Ridgway and Gregory Barden
}

The City of Columbus, Ohio, submitted a wet weather management plan in July 2005 (City of Columbus, 2005) in response to two consent orders from the State of Ohio. The second consent order, The Combined Sewer Overflow (CSO) Consent Order, mandated the development of a long term control plan (LTCP) in compliance with the requirements of the U. S. Environmental Protection Agency CSO Control Policy.

A critical component of the LTCP is the proposed Olentangy-Scioto Interceptor Sewer (OSIS) Augmentation Relief Sewer (OARS). The OARS will relieve the Olentangy Scioto Interceptor Sewer (OSIS) which is the principal trunk sewer that transports combined flow from the downtown Columbus sewersheds to the downstream wastewater treatment plants (WWTPs). The intent of OARS is to intercept and convey a significant amount of the wet weather flow from the OSIS in a separate conduit to the WWTPs for biological treatment which would eliminate or reduce overflows to the Scioto River from the downtown regulators in the OSIS system. Most significantly, the overflows from the Whittier Street storm standby tank (WSST) located on the OSIS system south of downtown Columbus, which cause $85 \%$ of all annual overflows, will be eliminated at the Whittier Street site for the typical-year (a standardized precipitation year developed in the LTCP for continuous model simulation). Also, there will be no CSO discharges anywhere in the system for the typical-year except at a new CSO farther south near the Jackson Pike WWTP, where four overflows during the typical-year are permitted. This new CSO will have a high

Cherian, M.P., A. Pandian, K. Ridgway and G. Barden. 2010. "Surge Analysis for the Proposed OSIS Augmentation Relief Sewer Tunnel. "Journal of Water Management Modeling R236-05. doi: 10.14796/JWMM.R236-05.

(C) CHI 2010 www.chijournal.org ISSN: 2292-6062 (Formerly in Dynamic Modeling of Urban Water Systems. ISBN: 978-0-9808853-3-0) 
rate treatment (HRT) plant associated with it, to provide treatment and disinfection. In addition to the above typical-year requirements required by the LTCP, the City has requested that OARS be designed to capture or convey the 10-y flow event (generated using recurrence-interval analysis of single events, Gheith et al., 2007) so that there are no overflows in the downtown regulators even for the 10 -y flow event.

The most significant component of the OARS project is a $23000 \mathrm{ft}$ $(7010 \mathrm{~m})$ tunnel approximately $150 \mathrm{ft}(45.8 \mathrm{~m})$ deep that is to carry the combined flow through downtown Columbus to the downstream project components. Flows from the OSIS are to be diverted to the OARS tunnel at three locations through a system of drop shafts, relief structures, and appurtenant structures such as tangential inlets and approach channels. The initial design of the OARS project, including the tunnel elements, was accomplished by means of a city-wide SWMM 4.4H model which had been developed over many years to evaluate the impacts of various LTCP projects. However, there was concern that the SWMM 4.4H model could not adequately simulate the surges that could occur in the OARS tunnel as a result of rapid filling of the tunnel. Significant surges could lead to elevated hydraulic grade lines (HGLs) at the connecting relief structures which in turn could cause unanticipated CSOs at the adjacent downtown regulators. In addition, there was need to evaluate the potential for air entrapment in the tunnel and to devise methods for releasing the air safely in order to prevent geysering.

Recognizing the need to conduct a surge-ventilation analysis for the OARS tunnel, the project design team selected the Transient Analysis Program (TAP) for this purpose. TAP is a computer program that calculates steady-state, gradually-varied, and rapidly-varied flow conditions in a system of open channels and closed conduits. TAP has been previously used to analyze CSO tunnel systems (Ridgway, 2008). This chapter details how TAP was applied to the OARS project, the interaction with the SWMM 4.4H model, and comparison of TAP results with those of SWMM $4.4 \mathrm{H}$.

\subsection{OARS Project Description}

A schematic of the principal components of OARS project is shown in Figure 5.1. Shaft 8 is the location of the most upstream relief structure and is also located at the upstream end of the tunnel. Shafts 6 and 5 are at intermediate locations and are offline to the main tunnel; they are connected to the main tunnel by adit tunnels. Shaft 5 is at the location of the WSST. Shaft 4 brings in flow from a different sewer. Shaft 3 is an access shaft; shaft 2 is the screen shaft 
and shaft 1 is the most downstream shaft which also houses a $75 \mathrm{mgd}$ ( $3286 \mathrm{~L} / \mathrm{s}$ ) pump station whose purpose is to dewater the tunnel between flow events. Flow from shaft 1 is first diverted to Jackson Pike WWTP through a surface conduit. When the capacity of the plant is exceeded, the flow then goes to an HRT. When both capacities are exceeded, flow is allowed to overflow to the Scioto River over a static weir. The OARS tunnel and connecting structures are scheduled to be operational in 2014; the HRT is expected to be completed in 2017.

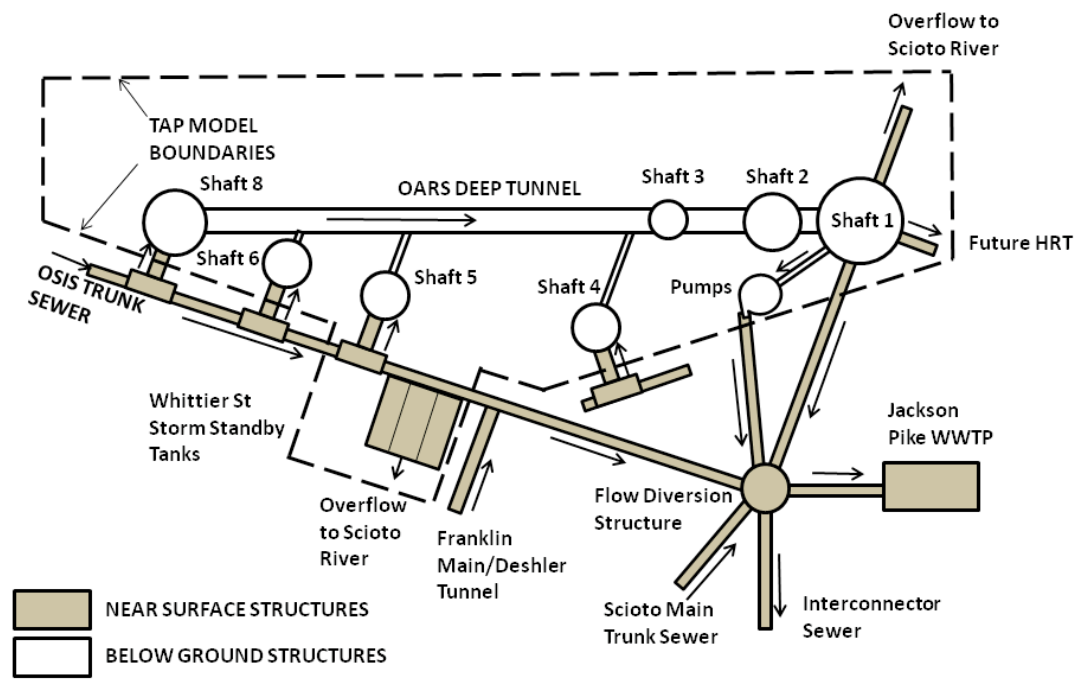

Figure 5.1 Schematic of the OARS project.

Two separate criteria are to be met by the OARS project: (i) no overflows at any regulator for the typical-year, except at the new CSO near the Jackson Pike WWTP (from the overflow weir at shaft 1) where four overflows for the typical-year are permitted; and (ii) no overflows from the downtown regulators for the 10-y event (overflows from WSST and shaft 1 are permitted).

\subsection{TAP and SWMM Model Interface}

The TAP program is computationally very intensive because of the small time steps that are selected by the program automatically; consequently it is not well suited to model large systems because of long run times. For this reason, TAP 
was used primarily to model the tunnel and the connecting structures only; it was then necessary to identify the appropriate boundaries of the TAP model and ensure compatibility across the boundaries with the SWMM 4.4H model.

The chosen TAP model boundary is shown in Figure 5.1 above. The WSST is included in the model since the tanks have significant storage which will impact the surge analysis. The inflows to shafts 8,6 and 4 and to the system from the OSIS just upstream of the shaft 5 relief structure were obtained from the SWMM 4.4H model as time-varying hydrographs. Similarly, outflow hydrographs just downstream of shaft 5 (to the OSIS) and from shaft 1 to the flow diversion structure (FDS) were also obtained from the SWMM 4.4H model.

There could be issues with the above approach to imposing boundary conditions. For example if the outflows from the system (downstream of shaft 5 , and from shaft 1 to FDS) were subject to backwater conditions, then utilizing only the outflow hydrographs as a boundary condition may not be sufficient. Fortunately, an examination of the flow and the HGL (from the SWMM 4.4H model) revealed no significant backwater impacts at these locations. If there were such impacts, it would be best to extend the model as far downstream as necessary where such impacts would be minimal. Such an approach is generally necessitated since it is difficult to develop reliable rating curves at intermediate locations as a result of transient conditions.

Similar problems could also be encountered at inflow boundaries as well. For this reason and for matching the flow and HGL elevations at the inflow and outflow locations, an iterative procedure between the TAP and SWMM 4.4H models was developed as described in Section 5.3.

\subsection{Iterative Procedure}

The imposition of the initial inflow and outflow hydrographs obtained from the SWMM $4.4 \mathrm{H}$ model as boundary conditions to the TAP model was only the first step of an iterative procedure to obtain an acceptable agreement between the two models in terms of flows and HGL elevations at the boundaries. This is because the TAP HGL output elevations obtained as a result of the imposing of the initial inflow and outflow hydrographs at the boundaries (the inflow locations were the upstream ends of approach channels to the tangential inlets and drop shafts) did not initially match those in the SWMM 4.4H model. Of course, one would not expect a match during the occurrence of surges, but a reasonable comparison in the HGL elevations should be expected during the period before and after surge occur. 
A significant reason for the discrepancy in the HGL elevations was due to differences in the head losses in the drop shaft and appurtenant structures (at all inflow locations) between the two models. The TAP model prescribed losses in the drop shaft system in accordance with data obtained from the results of a physical model study (Northwest Hydraulic Consultants, 2008). The most significant loss occurred across the narrow tangential inlets during surcharged conditions. It was difficult to simulate the required head losses in the SWMM $4.4 \mathrm{H}$ model simply by imposing the measured physical model loss coefficients as entrance/exit loss coefficients in the approach channel conduits. For this reason, artificial conduits were introduced in the SWMM 4.4H model downstream of each approach channel. The head losses across the conduits were adjusted (by changing the loss coefficients as required) such that the total head losses across the drop shaft systems in the SWMM 4.4H model approximately matched those indicated by the initial TAP model run during the time period that followed the surge occurrence (when the approach channels were surcharged and the flow conditions were quasi-steady). These changes in head losses altered the flow hydrographs in the boundary conduits of the SWMM $4.4 \mathrm{H}$ model which were then updated in the subsequent TAP run. The new head losses across the drop shafts indicated by this updated model was then imposed in the SWMM 4.4H model and the procedure repeated till reasonable match in the HGL was obtained at all boundary locations over the entire range of flow (except when surges occurred).

\subsection{Modeling Criteria and Scenarios for TAP}

Since TAP cannot be used for continuous simulations such as that for the typical-year (due to the long run times), two design events were considered for the TAP runs: (i) the largest event of the typical-year (the June 6th event) which is labeled herein as the 1-y event, and (ii) the 10-y event.

These events were run for each of two physical conditions for the OARS project: the 2014 conditions (without the HRT in operation) and the 2017 conditions (with the HRT in operation). The criterion for the 1-y event was that there should be no overflow at the WSST. The criterion for the 10-y event was that there should be no overflow at the downtown regulators. Since the regulators were not included in the TAP model, the second criterion above was satisfied by imposing specific maximum hydraulic grade line elevations at the boundaries of the model which do not cause the adjacent regulators to overflow (see Section 5.6). 


\subsection{Initial TAP Runs}

Initial TAP runs for the preliminary design of OARS $(30 \%$ completion design and plans) indicated significant surges in the system that had not been revealed by the SWMM 4.4H model. The $30 \%$ design was based on an $18 \mathrm{ft}(5.5 \mathrm{~m})$ diameter tunnel, $10 \mathrm{ft}(3 \mathrm{~m})$ diameter drop shafts, and appropriately proportioned structures such as de-aeration chambers, adit tunnels, tangential inlets, and approach channels. TAP runs indicated that in order to meet the objectives of the project, the tunnel would need to be $20 \mathrm{ft}(6.1 \mathrm{~m})$ diameter and the drop shafts were required to be $16 \mathrm{ft}(4.9 \mathrm{~m})$ diameter. The tangential inlet and approach channel dimensions had to be increased proportionately. A significant reason for the increased drop shaft diameter was the need to reduce the losses in tangential inlets.

In addition, there was need to allow the surges to overflow into dedicated surge storage shafts at each location, particularly for the 10 -y flow event. This would mitigate surge propagation into the approach channels and thus eliminate any impacts to the upstream collection systems. The $30 \mathrm{ft}(9.1 \mathrm{~m})$ construction shafts associated with each drop shaft will be left open (instead of being filled in) to act as surge storage shafts. The exception was at shaft 8 , the most upstream shaft, where the impacts of the surge and air venting were the worst. The surge storage shaft (construction shaft) at this location would be $48 \mathrm{ft}(14.6 \mathrm{~m})$ diameter. In addition, within this shaft, a $20 \mathrm{ft}(6.1 \mathrm{~m})$ diameter shaft located downstream of the $16 \mathrm{ft}(4.9 \mathrm{~m})$ diameter drop shaft would be dedicated for venting air.

In general, preliminary surge storage shaft volume requirements were determined by assessing the volume of overflow at the pertinent locations when no surge storage shaft was provided at that location. Vent shaft diameter was determined by using the rule of thumb approach that this diameter should be of the order of the tunnel diameter.

To further ensure that surge impacts would not propagate upstream, an overflow channel parallel to the approach channel (connected by a lateral weir in the wall of the approach channel) was provided to carry any excess flow to the storage shaft. All dimensions of structures including lengths and elevations of overflow weirs along the drop shafts, vent shaft and approach channels were determined using repeated runs of the TAP model. Figures 5.2 and 5.3 illustrate the surge control devices at shaft 8 . At shaft sites 4, 5 and 6 where the surge and vent issues are not as severe as those at shaft 8 , there is no separate vent shaft and the surge storage shaft is $30 \mathrm{ft}(9.1 \mathrm{~m})$ diameter. 


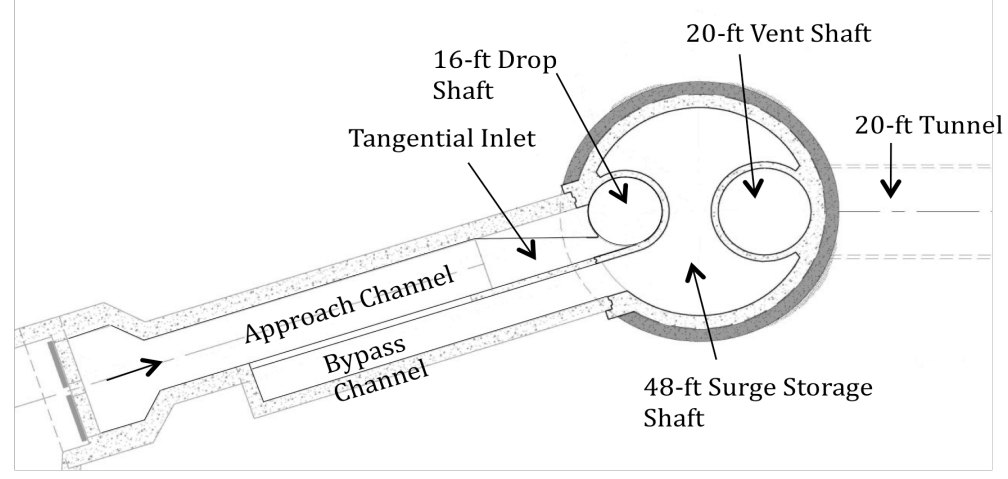

Figure 5.2 Plan view of shaft 8 features.

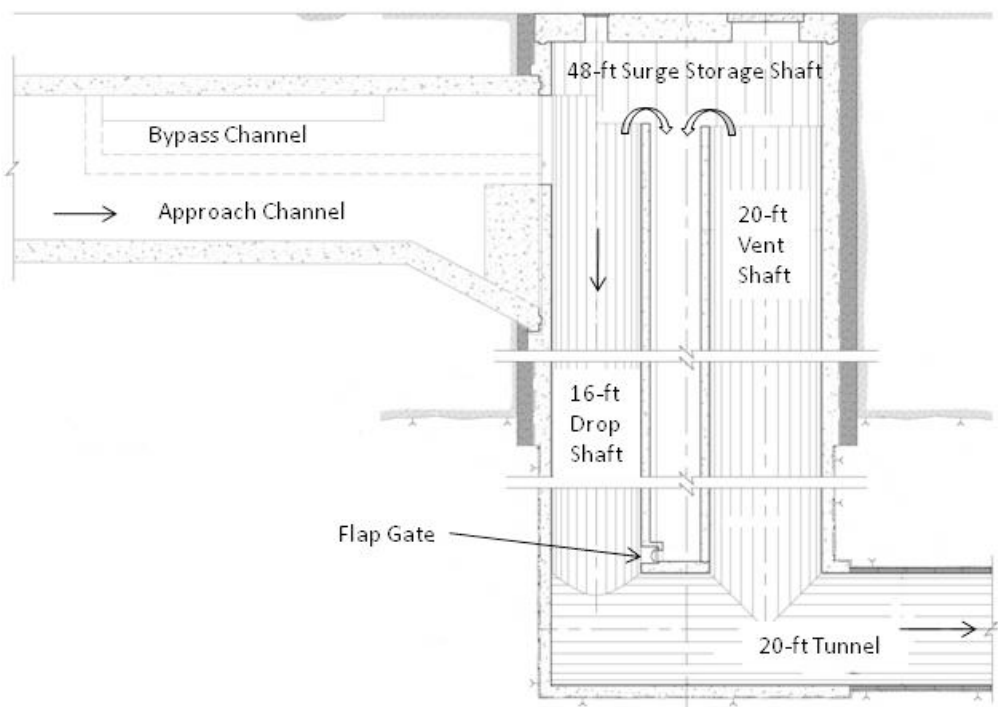

Figure 5.3 Elevation view of shaft 8 features.

\subsection{Maximum HGL Elevations at Boundaries}

An important goal of the TAP model was to design surge control measures (described above) such that the maximum surge-related HGL elevations at the model boundaries do not exceed the HGL elevations that would cause overflow 
at the adjacent regulators. This is particularly critical for the 10 -y event since the HGL elevations associated with the 10 -y event can be expected to be higher than for the 1-y event. The acceptable HGL elevations at the model boundaries were determined in the SWMM 4.4H model using a trial and error approach. First, the connections to the OARS tunnel were cut and the previously computed 10-y HGL elevations from the full model were imposed at the cut connections as free outfall conditions. Then the values of the 10-y HGL elevations for the entire period after the tunnel was full were raised in $0.5 \mathrm{ft}$ increments (at all the cut connections) until overflow just occurred at a regulator. Additional increases in HGL elevations were made appropriately until all regulators just overflowed. The resulting elevations were adjusted as required to develop the maximum acceptable HGL elevations at the TAP model boundaries. The acceptance criteria are shown in Table 5.1.

Table 5.1 Maximum acceptable HGL elevations.

\begin{tabular}{lc}
\hline \multicolumn{1}{c}{ Boundary Location } & Max. Acceptable HGL Elevation (ft) \\
\hline Shaft 4 & 713.5 \\
OSIS u/s WSST (shaft 5) & 709.4 \\
Shaft 6 & 711.5 \\
Shaft 8 & 712.9 \\
\hline
\end{tabular}

\subsection{Boundary Conditions}

The final inflow hydrographs to the OARS at the model boundaries were obtained from the SWMM 4.4H model following the iterative procedure described in Section 5.4 above. The inflow hydrographs were obtained for two flow conditions, the 1-y flow event and the 10-y flow event. The hydrographs were obtained at a $5 \mathrm{~min}$ time step, and wherever necessary the hydrographs were modified to remove instabilities that were apparent in the SWMM 4.4H output. There were no significant differences in the inflow hydrographs between the 2014 and 2017 conditions; consequently the same hydrographs were used for both conditions. The inflow hydrographs are shown in Figures 5.4 and 5.5.

The two flow hydrographs leaving the system (from the SWMM $4.4 \mathrm{H}$ model) are (i) the flow hydrograph in the conduit just downstream of the OARS relief structure at shaft 5 which is the flow continuing in the OSIS, and (ii) the flow hydrograph in the conduit from shaft 1 to the FDS. These outflow hydrographs (similar to those shown in Figures 5.4 and 5.5) were obtained from 


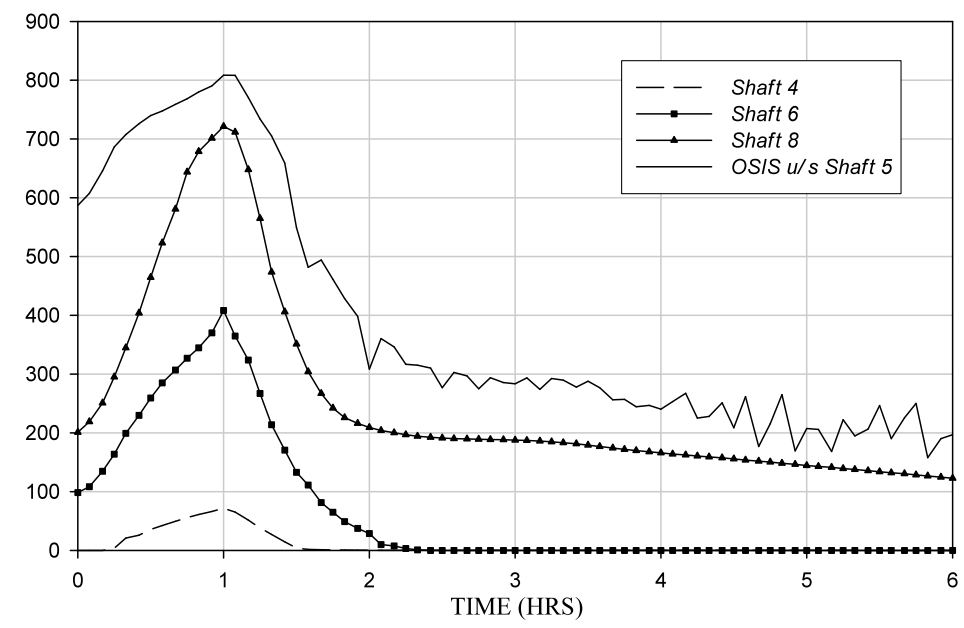

Figure 5.4 Inflow hydrographs-1-y event.

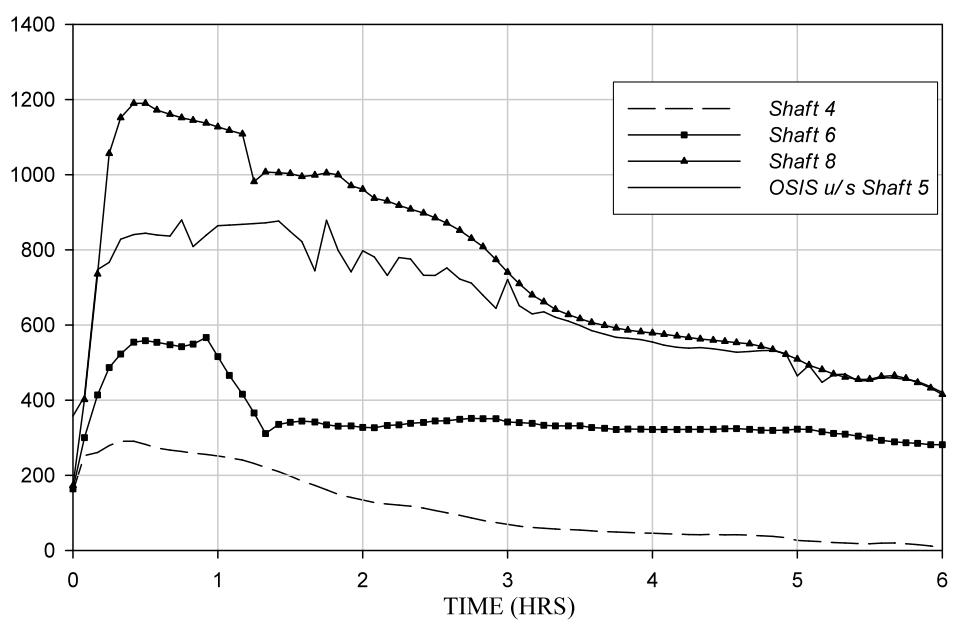

Figure 5.5 Inflow hydrographs-10-y event.

the SWMM 4.4H model and used in TAP. Note that the inflow and outflow hydrographs at the boundaries described herein changed during each iterative cycle for the synchronization of the TAP and SWMM 4.4H model results. 
The significant internal boundary conditions, modeled in TAP are (i) WSST overflow weir, $300 \mathrm{ft}(91.4 \mathrm{~m})$ long with a crest elevation $706.0 \mathrm{ft}(215.2 \mathrm{~m})$; (ii) shaft 1 overflow weir, $85 \mathrm{ft}(25.9 \mathrm{~m})$ long with a crest elevation of $699.4 \mathrm{ft}$ (213.2 m); (iii) shaft 1 pump schedule; and (iv) HRT flow schedule. The WSST and shaft 1 overflow weir lengths and crest elevations are assumed to be fixed and not variable in the simulations.

\subsection{Summary of Results}

The surge analysis results for the model scenarios in terms of maximum HGL elevations as computed by the TAP for each flow event (considering both the 2014 and 2017 condition) are summarized in Table 5.2. The TAP model shows that with the tunnel, connecting structure and surge control configurations as recommended, all HGL elevations are within the acceptable limits (compare with Table 5.1 above).

Table 5.2 TAP model HGL elevation summary.

\begin{tabular}{lcc}
\hline \multicolumn{1}{c}{ Boundary Location } & 1-y Event HGL Elevation $(\mathrm{ft})$ & 10-y Event HGL Elevation $(\mathrm{ft})$ \\
\hline Shaft 4 & 702.1 & 709.3 \\
OSIS u/s WSST (shaft 5) & 701.8 & 707.9 \\
Shaft 6 & 703.2 & 71.5 \\
Shaft 8 & 706.4 & 712.7 \\
\hline
\end{tabular}

\subsection{Results for the 1-y Event}

The time versus hydraulic grade line plots using TAP and SWMM 4.4H are shown in Figures 5.6 to 5.9 at all of the model boundaries for the 2014 conditions. Note that the TAP to SWMM comparison of the HGL is relatively good for the time periods well before and after the tunnel is full. For the short period just before and after the tunnel fills (the steep portion of the HGL plot), the TAP model displays oscillations in the approach channels due to surge formation during this period which is primarily because the surge storage shafts are not activated (the overflow weirs from the drop/vent shafts to the storage shafts are set relatively high) and consequently, the surges are not suppressed during the 1-y event. The SWMM model however does not display oscillations since it is not capable of simulating such rapidly varying hydraulic transients. At shaft 5 , the TAP results show no oscillation in the HGL of the approach channel as the overflow weir at shaft 5 is set lower to activate the storage shaft before the surge reaches the WSST. Since flow occurs over the weir and drops into the 
storage shaft, the surge does not propagate into the approach channel. The occurrence of surge during the 1-y event is not a critical issue as the maximum hydraulic grade line elevations are significantly lower than the acceptable levels. Note that there is no overflow at WSST since the HGL elevation is lower than the crest of the overflow weir $(706.0 \mathrm{ft}[215.2 \mathrm{~m}])$. The hydraulic grade line elevations for the 2017 conditions are significantly lower than that for the 2014 conditions (see typical result for shaft 4 in Figure 5.10) since the downstream HGL at shaft 1 for the 2017 conditions is controlled by the pipe invert elevation $(689.6 \mathrm{ft}[210.2 \mathrm{~m}])$ to the HRT as opposed to the overflow weir crest elevation $(699.4 \mathrm{ft}[213.2 \mathrm{~m}])$ at shaft 1 for the 2014 condition.

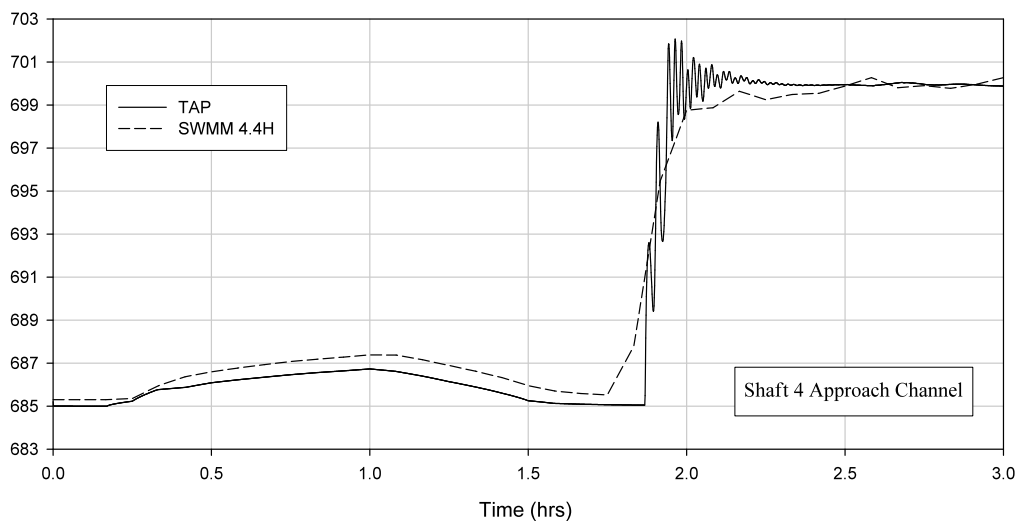

Figure 5.6 HGL comparison at shaft 4 (1-y event-2014).

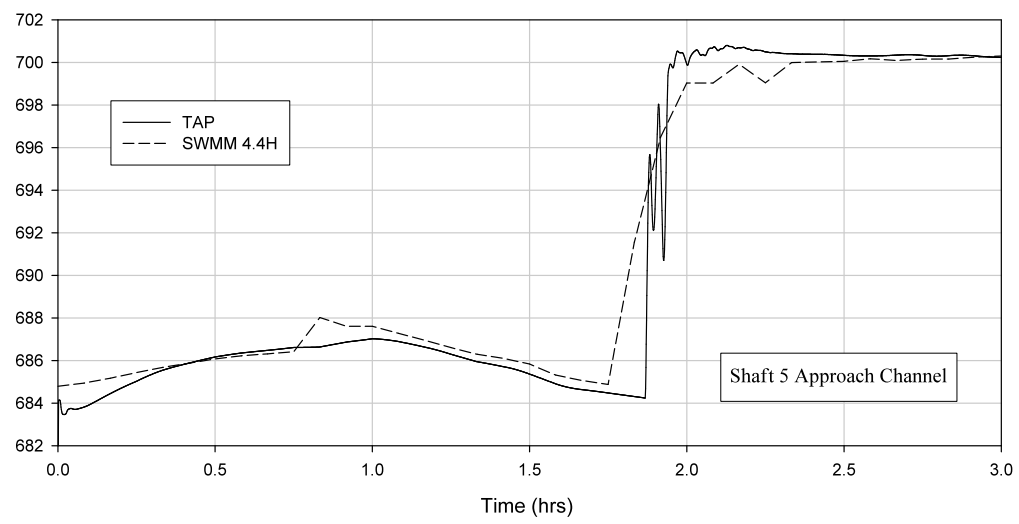

Figure 5.7 HGL comparison at shaft 5 (1-y event-2014). 


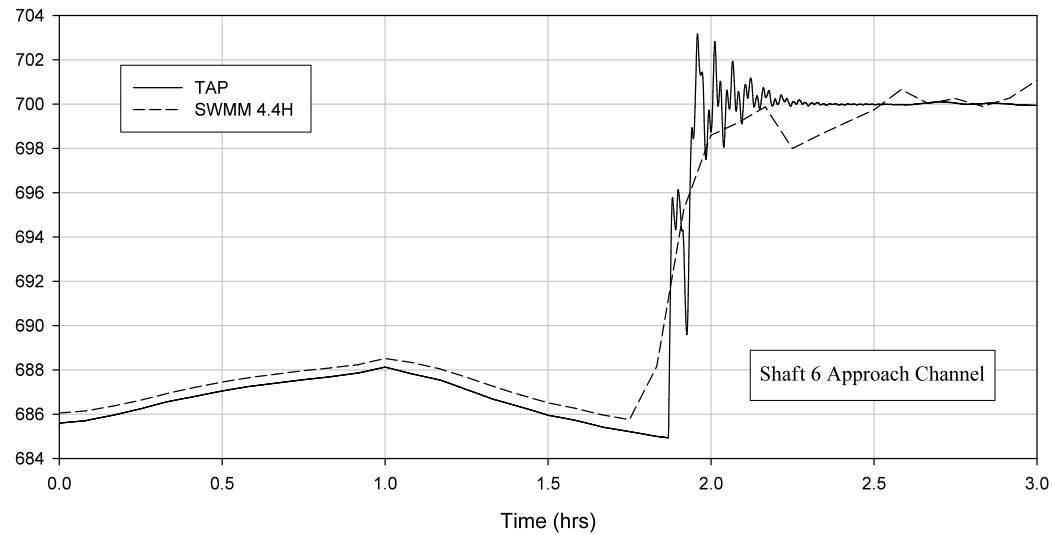

Figure 5.8 HGL comparison at shaft 6 (1-y event-2014).

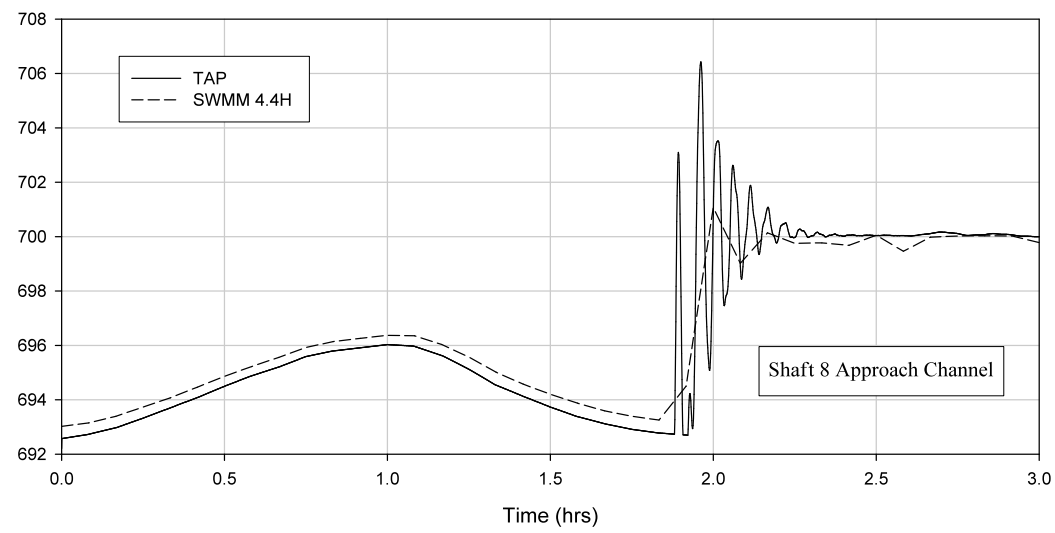

Figure 5.9 HGL comparison at shaft 8 (1-y event-2014). 


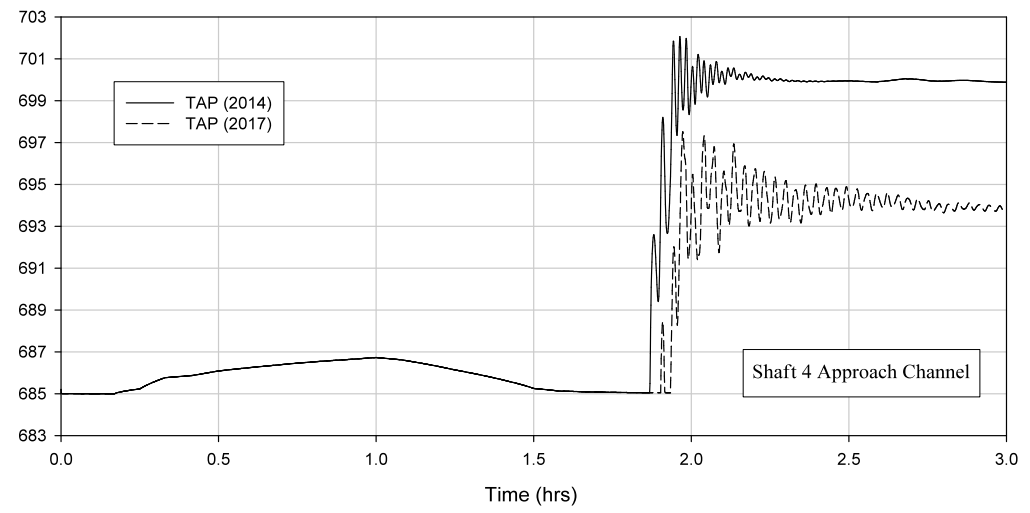

Figure 5.10 HGL comparison (1-y event-2014 and 2017).

One reason for the difference in the HGL elevations between TAP and SWMM 4.4H may be due to the procedure related to the conversion of the energy grade line elevations reported by TAP to HGL elevations. Since the approach channels in TAP are modeled as gates, the computed velocity head may not exactly represent the velocity head in the approach channel.

\subsection{Results for the 10-y Event}

The HGL versus time plots for the 10-y event using TAP and SWMM 4.4H are shown in Figures 5.11 to 5.14 at all of the model boundaries for the 2014 conditions. Note that the TAP to SWMM comparison is acceptable but not as good as that for the 1-y event.

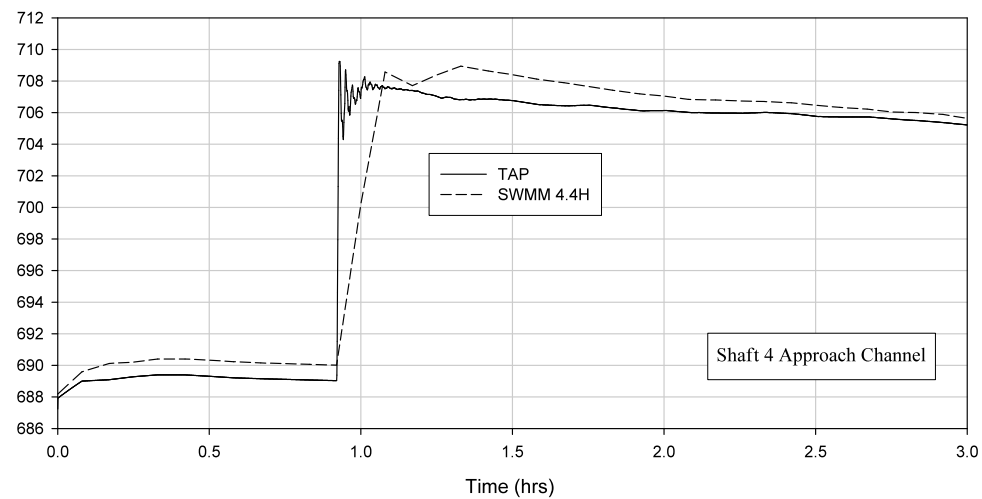

Figure 5.11 HGL comparison for shaft 4 (10-y event-2014). 


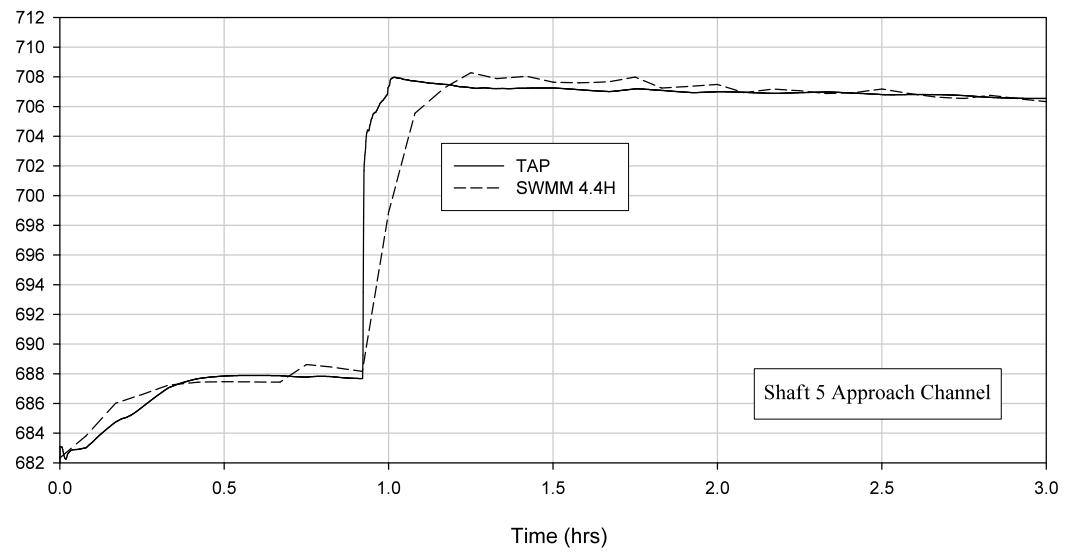

Figure 5.12 HGL comparison for shaft 5 (10-y event—2014).

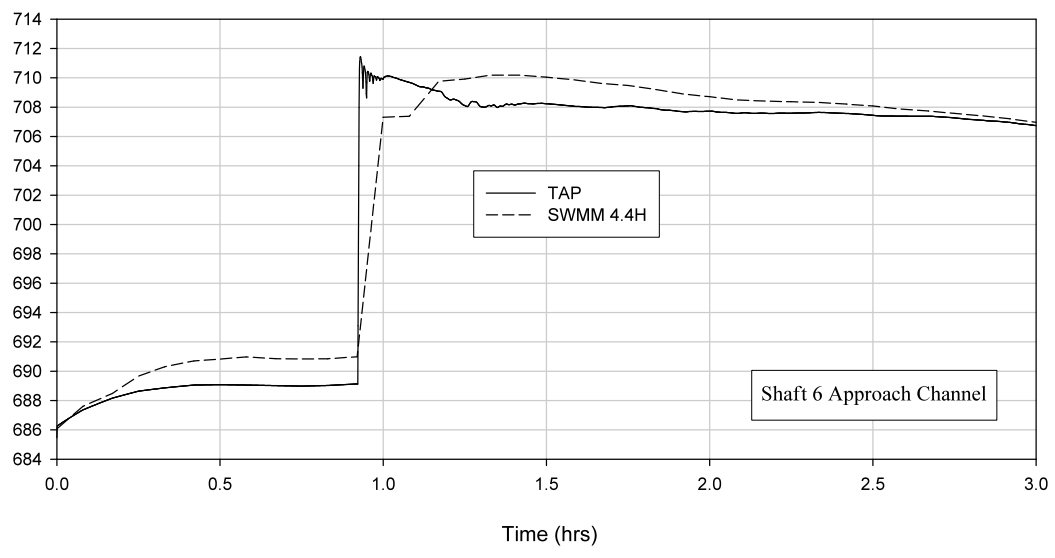

Figure 5.13 HGL comparison for shaft 6 (10-y event—2014). 


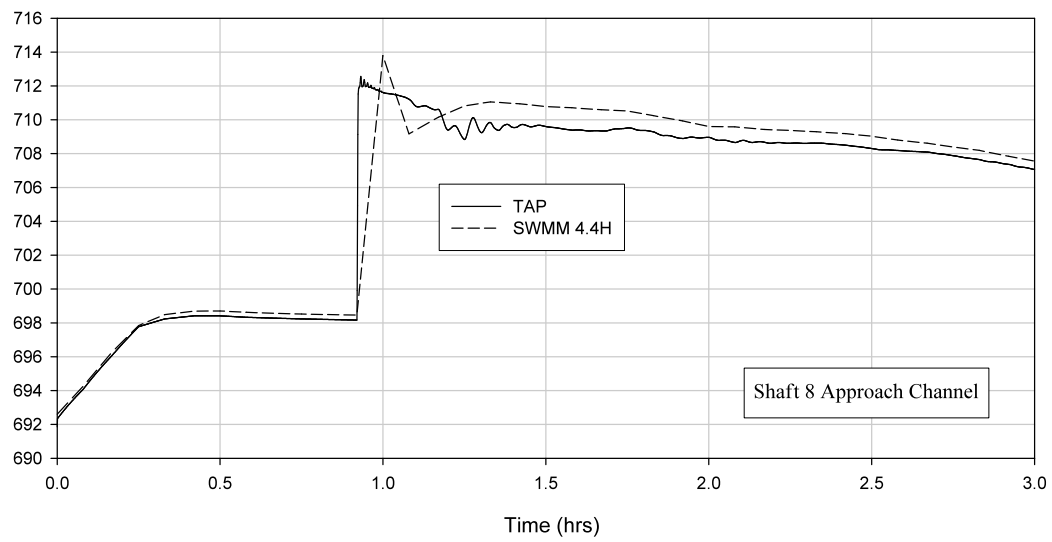

Figure 5.14 HGL comparison for shaft 8 (10-y event-2014).

Unlike the typical-year event results, the TAP model does not display significant oscillations for the 10 -y event; this is because all of surge storage shafts and bypass channels are active which suppresses surge formation and propagation to the approach channel and the boundaries. Additionally, the surge storage shafts are not full to the point of surcharging the associated overflow weirs (with the exception of shaft 5), which allows the flow in the storage shaft to be completely isolated from the tunnel system. In fact all of the overflow weir elevations from the drop/vent shafts to the storage shafts (with the exception of shaft 5) were deliberately set so that the storage shafts do not fill up during the event. As stated in Section 5.9, the weir elevation at shaft 5 that allows the flow to enter the storage shaft was set lower in order to ensure that the available storage in the shaft is fully utilized before significant flow backs up into the tanks. At shaft 5, the full utilization of the surge storage shaft is not an issue since any surge that occurs after it is full would be stored in the WSST.

There are no significant differences in the HGL plots between the 2014 and 2017 conditions (see Figure 5.15) since the overflow weirs at shaft 1 and WSST are all active for both conditions.

The surge suppression ability of the storage shafts is illustrated by the comparison of the HGL elevation plots at shaft 8 with and without the surge storage shaft at this location for the 10-y event, 2014 conditions (see Figure 5.16). Without the surge storage at shaft 8 , the HGL elevation far exceeds the maximum permissible value shown in Table 5.2 due to the significant surges at that location. 


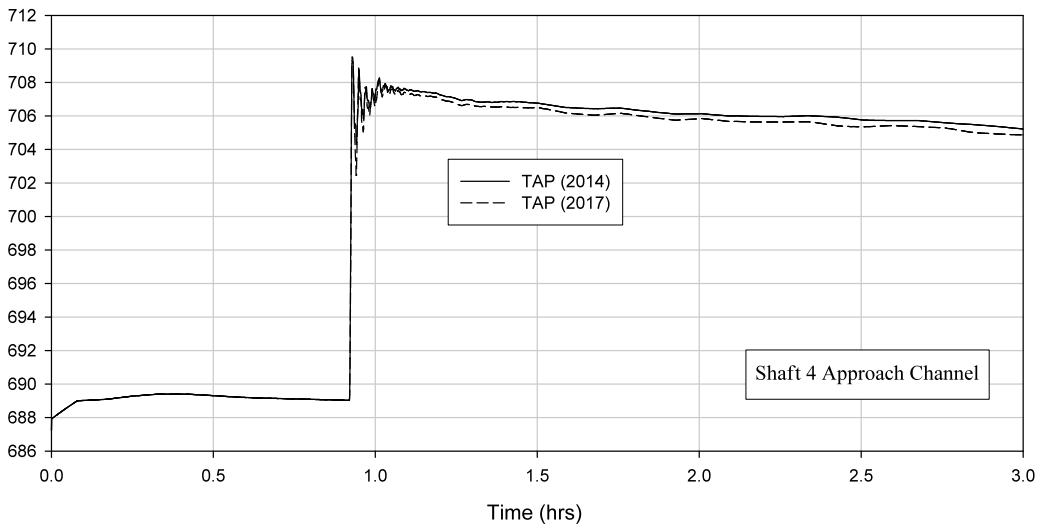

Figure 5.15 HGL comparison for shaft 8 (10-y event-2014 and 2017).

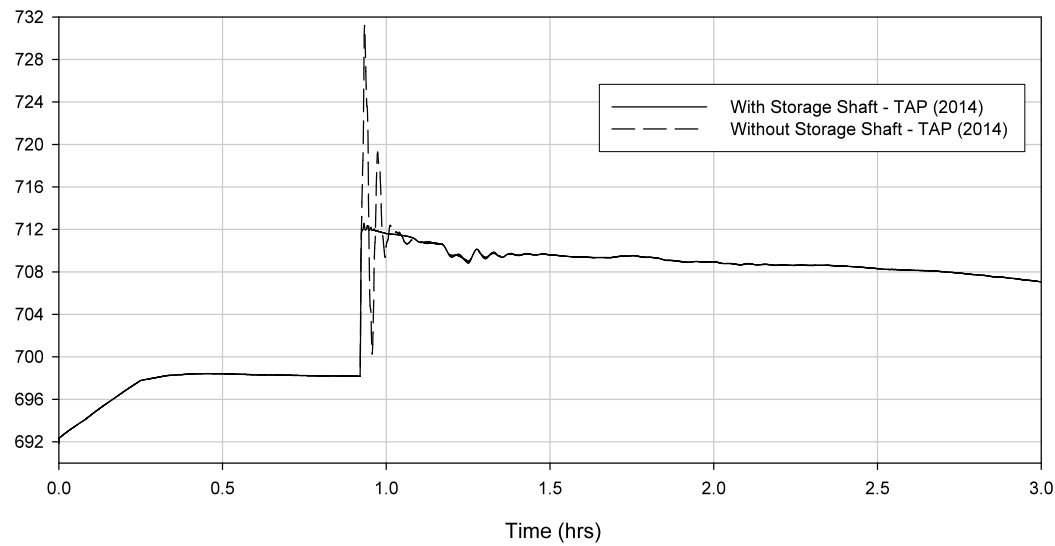

Figure 5.16 HGL comparison with and without surge storage at shaft 8

\subsection{Tunnel $30 \%$ and $60 \%$ Full Initial Conditions}

The TAP model was run for the 10-y 2014 conditions using two additional initial conditions: (i) $30 \%$ full tunnel, and (ii) $60 \%$ full tunnel. The principal TAP results are shown in Table 5.3. The maximum acceptable grade line elevations at the upstream boundaries are not exceeded (compare with Table 5.1 above). This is mainly because significant overflow occurs at the WSST overflow weir which limits the HGLs at the upstream boundaries. 
Table 5.3 HGL elevations (10-y event-2014): partially full tunnel.

\begin{tabular}{lcc}
\hline Boundary Location & $30 \%$ Full Initial HGL Elevation (ft) & $60 \%$ Full Initial HGL Elevation (ft) \\
\hline Shaft 4 & 709.3 & 709.9 \\
OSIS u/s WSST (shaft 5) & 707.9 & 708.0 \\
Shaft 6 & 711.3 & 711.1 \\
Shaft 8 & 712.8 & 712.7 \\
\hline
\end{tabular}

\subsection{Results with the $18 \mathrm{ft}(5.5 \mathrm{~m})$ Tunnel}

A TAP run was made with an $18 \mathrm{ft}(5.5 \mathrm{~m})$ tunnel diameter for the 10 -y event, 2014 conditions. The tunnel was assumed to be initially empty. It is further assumed that the inflows at the model boundaries are the same as that for the 20 $\mathrm{ft}(6.1 \mathrm{~m})$ tunnel. The intent of this scenario is to demonstrate the impact of the smaller diameter tunnel on the HGL elevations at the model boundaries. The results of this run are shown in Table 5.4.

Table 5.4 HGL elevations (10-y event-2014) with $18 \mathrm{ft}(5.5 \mathrm{~m})$ tunnel.

\begin{tabular}{lcc}
\hline \multicolumn{1}{c}{ Boundary Location } & Max. Acceptable HGL Elevation (ft) & 10-y Event HGL Elevation $(\mathrm{ft})$ \\
\hline Shaft 4 & 713.5 & 710.3 \\
OSIS u/s WSST (shaft 5) & 709.4 & 708.4 \\
Shaft 6 & 711.5 & 713.9 \\
Shaft 8 & 712.9 & 715.3 \\
\hline
\end{tabular}

It is interesting to note that the $18 \mathrm{ft}(5.5 \mathrm{~m})$ tunnel does not satisfy the minimum acceptable HGL criteria at shafts 6 and 8 . The comparison plots of the HGLs with the $18 \mathrm{ft}(5.5 \mathrm{~m})$ and $20 \mathrm{ft}(6.1 \mathrm{~m})$ tunnels are shown for shaft 8 in Figure 5.17.

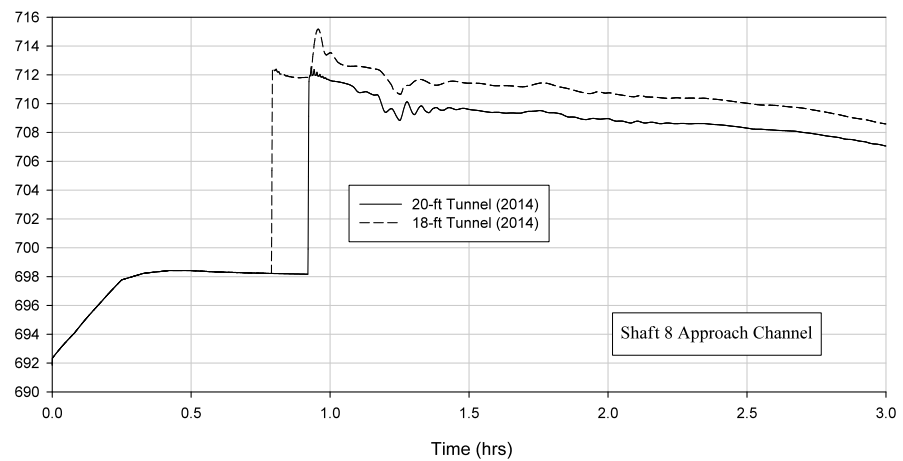

Figure 5.17 HGL elevations (20 ft tunnels and $18 \mathrm{ft}$ tunnels; $10-\mathrm{y}$ event-2014). 
With the $18 \mathrm{ft}(5.5 \mathrm{~m})$ tunnel, the available surge storage volumes at all shaft locations become fully utilized earlier in time since the tunnel gets full earlier (owing to the smaller storage volume in the tunnel). Since the inflow does not drop off significantly just after the tunnel fills and there is no surge storage available at this time, the HGL rises to accommodate the incoming flow.

\subsection{Conclusions}

The TAP model was successfully used to conduct surge analysis for the OARS tunnel. It was used to design and evaluate surge control measures to effectively mitigate surge propagation to the upstream collection system and thereby ensure attainment of all project objectives. The most significant features that led to containment of the surge and suppression of the HGL elevations at the connection to the surface sewers were the use of larger sized drop shafts, appurtenances and tunnel diameter than originally proposed, and the provision of surge storage shafts. A procedure was devised to ensure the overall conformity of the TAP hydraulic grade lines with those computed using the city-wide SWMM 4.4H model. This process also led to improvements in the SWMM $4.4 \mathrm{H}$ model since head losses through the various elements of the drop structures which were not included in the initial SWMM 4.4H model were incorporated to match those given by the physical model tests.

\section{Acknowledgments}

The authors acknowledge the contributions of Taymour El-Hosseiny and Karen Reinhart in running the SWMM 4.4H model for the project. We would like to recognize the leadership role provided by Dax Blake of the City of Columbus, Ohio, in the conduct of the surge analysis.

\section{References}

City of Columbus Department of Public Utilities Division of Sewage and Drainage, 2005, Wet Weather Management Plan.

Gheith, H., M. Carmichael, G. Barden and M.P. Cherian. 2007. "Determining Peak Flow Recurrence in Combined Basins with Limited Flow Data Using Genetic Algorithm Calibration." Journal of Water Management Modeling R228-25. doi: 10.14796/JWMM.R228-25. 
Northwest Hydraulic Consultants, December 2008, OARS Drop Shaft, Physical Hydraulic Model Study, Final Report.

Ridgway, K. 2008. "Evaluating Surge Potential in CSO Tunnels." Journal of Water Management Modeling R235-14. doi: 10.14796/JWMM.R235-14. 